the generator external control points several months after implantation.

There have been no further breakages of the catheter leads since both stylets have been withdrawn.

So far, of the 53 Medtronic generators which we have implanted since October 1964 only one has failed. Thirtythree have been in use for more than six months (see bar Chart) without failure. To date, our duration of pacing has not taken the majority of our patients into the phase of normal battery depletion. We have, however, had no generator or catheter failures since May 1966. In an attempt to monitor the function of the generators we have been recording the pacemaker rate at intervals of two to three months. We also hope that the measurement of generator pulse characteristics will provide a more accurate estimate of battery depletion. However, measurement of pacemaker rate may be an equally reliable index of battery function.

Twelve patients in this series presented with a diagnosis of intermittent complete heart block. They were also treated with the standard fixed-rate pacemaker, and 11 were alive and well at the time of writing. The remaining patient died after prostatectomy. In other words, patients with intermittent block in this series were satisfactorily. treated with a fixed-rate pacemaker. There may, however, be a case for using a "demand" pacemaker in younger patients.

It is our experience that the Medtronic endocardial implantable pacemaker is reliable and offers an effective remedy for chronic complete heart block. This is also the finding of other workers (Castberg and Rasmussen, 1963 ; Marchand et al., 1967).

\section{Summary}

Forty-four patients with chronic complete heart block have been treated by the insertion of the fixed-rate ChardackGreatbatch endocardial pacemaker.

The preoperative mortality was nil, the postoperative morbldity low.
Of the 53 generators implanted there was one failure $(1.9 \%)$.

There were six catheter failures $(11.3 \%)$, all at the beginning of the series, owing to a steel stylet being left inside each catheter.

There have been no catheter or generator failures since May 1966.

The cases reported in this series were treated in four major hospitals in the Glasgow area, and a considerable proportion of the initial management and subsequent follow-up of these patients has been the responsibility of several of our medical and surgical colleagues. We are glad to have this opportunity of acknowledging their collaboration and their permission to refer to cases under their care. We wish, in particular, to thank Professor W. A. Mackay (Glasgow Royal Infirmary), Dr. R. M. Thomson (Glasgow Royal Infirmary), Mr. R. S. Barclay (Mearnskirk Hospital), Dr. A. S. Rogen (Stobhill General Hospital), Dr. J. A. Kennedy (Glasgow Royal Infirmary), Dr. A. J. V. Cameron (Western Infirmary), Dr. A. C. Kenmure (Western Infirmary), and Mr. M. A. Turner (Western Infirmary).

\section{REFERENCES}

Bain, W. H., Forbes, W., Greene, D., Shaw, G. B., and Thomson, R. M (1967). Scot. med. F., 12, 295.

Castberg, T., and Rasmussen, K. N. (1963). Acta chir. scand., 125, 557 Chardack, W. M., Gage, A. A., and Greatbatch, W. (1960). Surgery, 48.

643., R., and Senning, A. (1960). In Medical Electronics, edited by C. N. Smyth, p. 253. London.

Fort, M. L., and Sharp, J. T. (1965). Amer. 7. Cardiol., 16, 610.

Furman, S. (1966). Amer. F. Cardiol., 17, 439.

Furman, S., Escher, D. J. W., Schwedel, J. B., and Solomon, N. (1966). Amer. Heart F., $71,408$.

Glass, H., Shaw, G., and Smith, G. (1963a). Lancet, 1, 684.

Glass, H., Shaw, G., and Smith, G. (1963b). Scot. med. 7., 8, 254.

Knuckey, L., McDonald, R., and Sloman, G. (1965). Brit. Heart 7., 27, 483.

Lagergren, H., et al. (1966). Surgery, 59, 494. chir. scand., 125, 562

Marchand, P., Jaros, G. G., and Obel, I. W. P. (1967). S. Afr. med. .., 41,23 .

Morris, J. J., jun., Whalen, R. E., McIntosh, H. D., Thompson, H. K., Brown, I. W., jun., and Young, W. G., jun. (1967). Circulation, 36, 587.

Parsonnet, V., Zucker, I. R., Gilbert, L., and Asa, M. M. (1962). Amer. 7. Cardiol., 10, 261 .

Siddons, H., and Davies, J. G. (1963). Lancet, 2, 1204

Zoll, P. M., and Linenthal, A. J. (1960). Circulation, 22, 341.

Zoll, P. M., and Linenthal, A. J. (1963). Circulation, 28, 455.

\title{
Porter's Neck
}

LAURENCE F. LEVY,* M.SC., M.B., B.S., F.R.C.S., F.A.C.S.

Brtt. med. J., 1968, 2, 16-19

Several million sacks of mealie meal are produced annually in Rhodesia together with almost as many bags of beans, monkey auts, potatoes, fruits, etc. A very large proportion of these sacks are manhandled from granary to truck, from truck to salesroom, and from salesroom to consumer. This transportation is often performed by one man carrying the sack on his head. The usual routine is for four men to stand at the corners of a 200-lb. (90.7-kg.) bag with the porter just in front of them. At a given signal the four loaders hoist the bag into the air and the porter quickly walks underneath. The sack is then gently lowered on to his head, where it balances, steadied by his hands, until he arrives at his destination.

Once loaded, the porter walks at a steady pace towards his objective. Up to 30 yards ( 27 metres) is a convenient distance, well within the range of the ordinary porter-if the distance is Increased to 50 yards (46 metres), most find difficulty in covering it without strain. When he arrives at his unloading point the porter leans slightly forward and eases the sack off his head with his hands.

Difficulty occasionally arises at the moment of loading if the loaders drop the sack too quickly, or if the porter does not get the centre of gravity of the sack more or less vertically over the articular facets of the foramen magnum, or simply if the sack is too heavy for an ageing neck. Trouble may arise during the journey to the unloading point if the man should slip or fall or lose his balance through fatigue, while it sometimes happens that some jolt while unloading causes loss of balance and injury.

In the event of an accident, and if he is lucky, the porter may escape with nothing worse than a badly strained and painful neck which may put him off work for some days; if he is less lucky the injury may be more serious and he may suffer fracture or dislocation of the bones or discs of the neck with injury to the spinal cord. The disaster may be compounded by the bag landing on top of him.

\section{Incidence}

Over the past 10 years 13 such serious injuries have been seen on the neurosurgical ward at the Harare Central Hospital, Salisbury, and one further case was brought to the hospital

- Consultant Neurosurgeon, Salisbury Hospitals Group and Department of Surgery, University College of Rhodesia. 
dead (Table 1). Five of these injuries occurred while the porter was being loaded, five while the victim was walking with the sack in place though without any history of a jolt or fall, three when the patient tripped and fell while carrying the bag, and one during unloading. Two of the victims were females. One was walking with a heavy load of firewood balanced on her head when she tripped and fell; the other was being loaded with a sack at her home.

TABLE I.-Fourteen Cervical Injuries with Fracture or Cord Damage Due

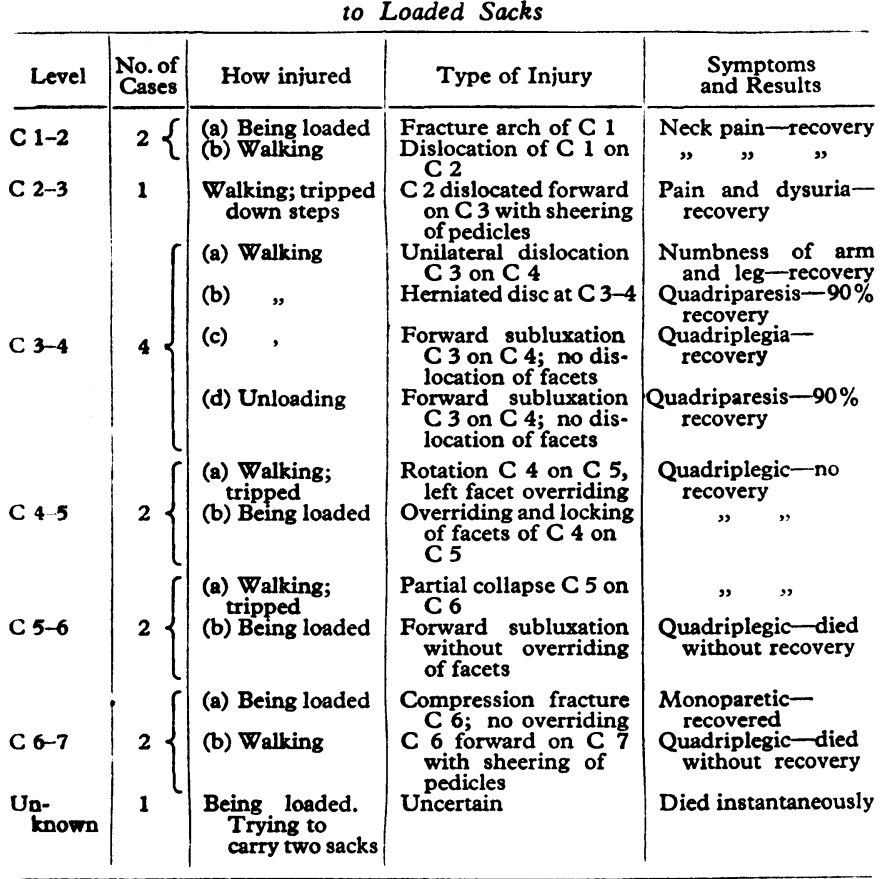

Two patients showed no bony injury. One of these was the man who was brought to the hospital dead. He had been enjoying a Saturday afternoon joke with his friends, whom he bet that he could easily carry two sacks on his head. The first sack had been safely loaded and the second was just being placed, when he collapsed and died. At post-mortem examination no fracture of the cervical bodies could be demonstrated, but some subdural and epidural blood revealed the presence of damage to the neck. No other cause of death could be determined. Unfortunately the cord was not retained for examination, but the presumption must be that he suffered a severe traumatic injury to the spinal cord, probably by disc herniation without bony dislocation. This hypothesis is borne out by another patient who suddenly became quadriplegic while walkIng (C $3-4$, b). Myelography revealed the presence of a herniated intervertebral disc at $C 3-4$, and presumably the sudden backward rupture of this disc on to the cord was responsible for the neurological picture. The remaining cases showed varying degrees of fracture and fracture-dislocation, often with overriding of the articular facets. At the $C 1$ to C 3-4 levels the injuries were all of such a nature as to produce minimal or no damage to the spinal cord. Only two out of seven such cases were mildly though permanently paretic; below that level overriding of the facets or collapse of a vertebral body produced permanent quadriplegia in five out of six cases.

\section{Site of Injury}

Whether the injuries occurred while the patient was being loaded, while he was walking with or without tripping, or while he was unloading seems to have little bearing on the site of the injury, while the factors responsible for determining at which level the spine will give way are obscure. However, sack injuries show a definite predilection for the upper as opposed to the lower cervical regions-the area most commonly damaged in neck injury due to other causes. Of the sack injuries, $58 \%$ involved the C 1 to $C 3-4$ regions, compared with only $14 \%$ when all cases of neck injury (50 in number) due to other causes are considered (Table II) $(0.01>\mathrm{P}>0.001$ $\left(\chi^{2}=9.93\right)$ for the $C 1$ to $C 3-4$ levels). (Injuries are recorded at the disc level rather than at one vertebral level because it is there that vertebral body movement one on the other with disc prolapse causes the injury by narrowing the canal. It is this movement which is as important in the production of spinal cord or nerve root pressure as bony collapse.)

TABLE II.-Distribution of 50 Cervical Injuries with Fracture or Cord Damage (Due to Other Causes)

\begin{tabular}{|c|c|c|c|c|c|c|c|}
\hline $\begin{array}{l}\text { Level } \ldots \\
\text { No. of cases.. }\end{array}$ & $\mathrm{C}_{3} 1-2$ & $\mathrm{C}_{2}^{2-3}$ & $\mathrm{C}_{2} 3-4$ & $C_{11}-5$ & $C_{13}^{C_{13}-6}$ & $C_{17} 6-7$ & $\underset{2}{C} 7-T^{\prime}$ \\
\hline
\end{tabular}

It is difficult to know why sack injuries are more prone to involve the upper regions of the cervical canal when other cervical injuries tend to localize lower down. In all these cases little is known about the actual injury, as it happens so quickly. The victim's recollection of the incident is vague, while the description given by onlookers is invariably poor. I believe, however, that the embedding of the victim's head within the substance of the sack as it sags slightly on either side is important in these transportation injuries, since the head cannot move independently of the sack so long as the latter remains in position. Indeed, what happens to the neck must be largely governed by the centre of gravity and momentum or lack of momentum of the sack. For example, if the body should fall to one side and turn slightly is one leg gives way, the head will remain fixed owing to the inertia of the sack, and thus the injury to the neck may be a forced twisting, which renders it more likely to give way at its point of maximum rotation in the upper levels than lower down. On the other hand, if the victim trips and falls forwards or backwards, forced flexion or extension is likely to produce an injury at the most mobile level for such a movement-namely, the lower cervical levels. This may account for the fact that in the "all other causes" group (Table II), where many of the injuries are diving or similar accidents, the majority occurred at the C 4-7 levels. Most occurred at C 6-7, though in the series of Norton (1962) C 5-6 was most frequently involved.

Niemeyer and Penning (1963) measured the mobility of the joints of the cervical spine and found maximum anteroposterior

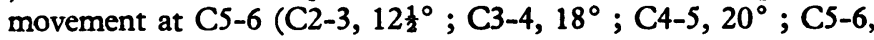
$21 \frac{1}{2}^{\circ}$; C6-7, $15 \frac{1}{2}^{\circ}$; C7-D1, $10^{\circ}$ ), while the fact that the C5-6 disc is most commonly affected by osteoarthritic processes suggests that this joint is subjected to maximum strain (Pallis et al., 1954) from maximum movement, and may well be more likely to give way than other levels. At the same time the varying thicknesses of the discs in the cervical column may be of importance in so far as a thicker disc requiring longer supporting ligaments may produce a more unstable joint than thinner discs, and this may increase the chance of injury occurring at the lower levels in hyperextension and hyperflexion accidents. Todd and Pyle (1928) found that the thickness of the discs in the adult cervical column increased towards the lower levels (thickness of discs below C2-3.7 mm., C3-4.0 mm., C4-4.4 mm., C5-4.8 mm., C6-5.6 mm., C7-4.4 mm.).

\section{X-ray Examination}

Seven porters selected at random were subjected to a cervical spine $x$-ray examination, first when standing completely relaxed and then when standing with a $200-\mathrm{lb}$. $(90.7 \mathrm{~kg}$.) sack on their heads. Examination of the resting $x$-ray films of the men (see Fig.), none of whom made any complaint regarding their neck, 
showed that four had a normal lordosis, one had a normal lordosis with angulation forward at C5-6 (No. 4), one had straightening (No. 6), and one had straightening with a forward angulation at C4-5 (No. 7). This is in keeping with the findings of Juhl et al. (1962) in 116 " normal " persons, 70 of whom had a convex anterior curve, 22 had straightening, 16 had a reversal of the curve, and 8 had forward angulation as well.

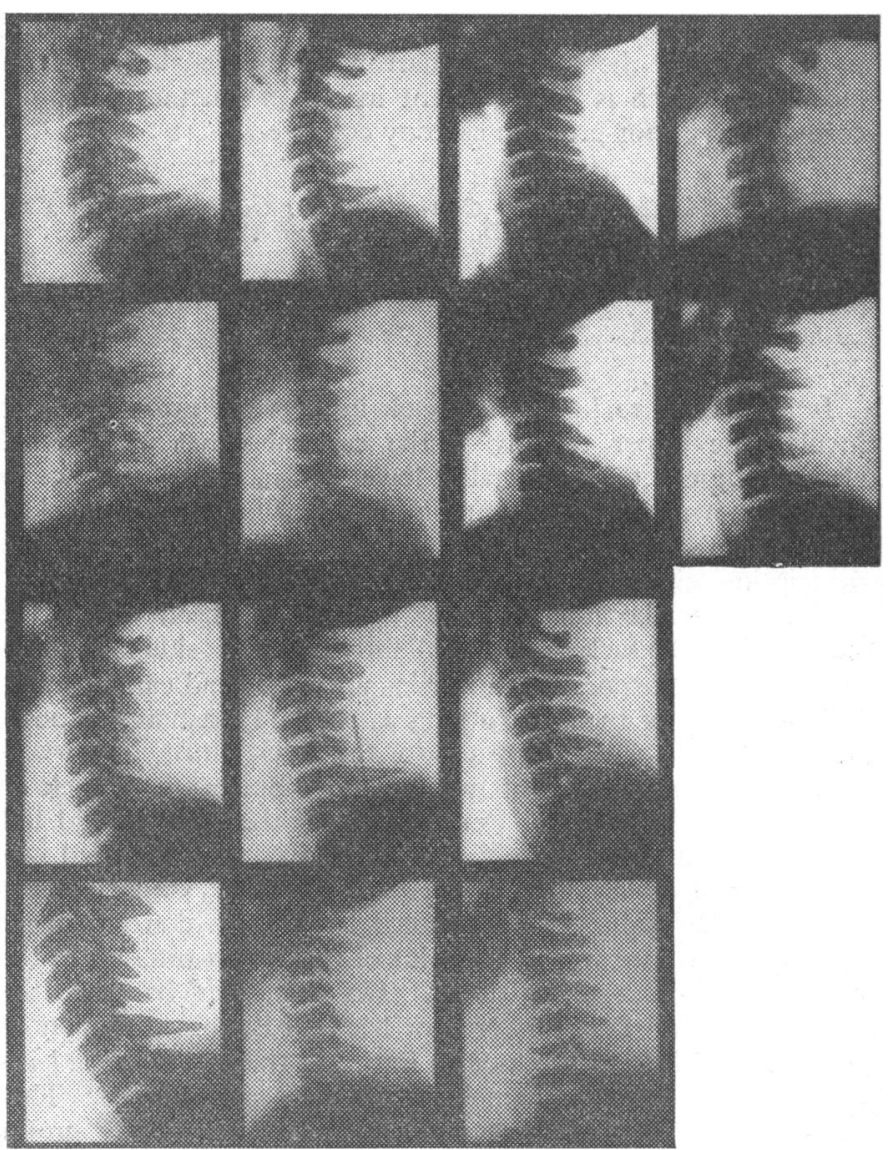

Lateral cervical spine $x$-ray films of seven porters standing relaxed (first and third lines) and loaded with 200-lb. (90.7-kg.) sack (second and fourth lines).

Examination of the $x$-ray films taken after the porters had been loaded shows that the bodies of the vertebrae and the intervertebral discs straighten and assume a vertical position and bear the weight down a straight line like the blocks of a pillar. The ligaments and muscles are thus relieved of some of the stress by this assumption of the vertical position. The spinous processes of the vertebrae move apart as the normal lordosis disappears, but none so markedly as those of $\mathrm{C} 1-2$ as the atlas carries the vertex of the head forward over the upright pillar. The discs become compressed and the spaces narrowed, and undoubtedly the integrity of the disc and its surrounding ligaments plays a considerable part in the stability of this pillar mechanism. In two cases disc disease caused forward angulation; in one in the presence of previous straightening (No. 6) and in the other as an exaggeration of an already present forward angulation (No. 7). In these cases the upper neck hyperextends particularly at the C 1-2 level in an effort to compensate for this forward angulation of the pillar and the vertebral column assumes a somewhat $S$-shaped appearance. The forward tilting of the vertebral body on the diseased disc reduces the normal amount of overriding of the upper articular facet behind the lower one (No. 7) and must predispose the owner to injury. Such liability to injury may not be present at the point of forward angulation, but may be present at the point of compensatory hyperextension in the upper cervical levels where the optimum position for the transmission of such forces can no longer be adopted.

\section{Prognosis}

The prognosis in injury to the neck varies immensely with the level involved, regardless of the cause. When the results of all 63 injuries are considered (Tables I and II) it is found that $50 \%$ of the injuries from C4-5 downwards resulted in permanent quadriplegia. By contrast, of the fractures between $\mathrm{C} 1$ and C3-4 there was only one permanent quadriplegic in 14 cases. Similarly Rogers (1957), discussing nine cases of odontoid fracture, reported seven without symptoms and two quadriparetic, while Blockey and Purser (1956), reviewing 51 cases, found no symptoms in 39 and only minor afflictions in the majority of the remainder. It might be thought that an injury high up in the neck would result in instantaneous death; however, this does not appear to be so. This is to some extent due to the larger cross-sectional area of the spinal canal at that level, compared with lower down. The anteroposterior diameter of the normal cervical spinal canal is at its maximum at $\mathrm{Cl}$ (21.5 $\mathrm{mm}$.) and tapers off rapidly to $17.5 \mathrm{~mm}$. at $\mathrm{C4}$, after which it remains more or less constant (Payne, 1959). The anteroposterior diameter of the cord is $12.5 \mathrm{~mm}$. at the medullocervical junction, and $9.5 \mathrm{~mm}$. at C3-4 tapering to $8 \mathrm{~mm}$. at C6-7 (Crandall and Hanafee, 1964), so that anteroposteriorly there is less than $1 \mathrm{~cm}$. of space available throughout the length of the cervical spinal canal for movement of the vertebrae one upon the other without constricting the cord. However, the cross-sectional area of the spinal canal is much larger in the C1-2 regions than elsewhere (Table III).

TABLE III.-Mean Cross-sectional Area of the Spinal Canal at Various Levels"

\begin{tabular}{|c|c|c|c|c|c|c|}
\hline $\begin{array}{l}\text { Level } . . \\
\text { Area }(s q . \mathrm{cm} .)\end{array}$ & $\begin{array}{l}C 1 \\
4.66\end{array}$ & $\begin{array}{l}\mathrm{CL}_{3.09} \\
\end{array}$ & $\begin{array}{l}\text { C } 3 \\
2 \cdot 57\end{array}$ & $\underset{2.54}{C 4}$ & $\begin{array}{c}\text { C5 } \\
2 \cdot 70\end{array}$ & $\begin{array}{r}\text { C.65 } \\
\text { C. }\end{array}$ \\
\hline
\end{tabular}

- The cross-sectional area of the spinal canal at various levels was estimated by taking 13 complete cervical spines extending from $C_{X \text {. }}$ to $C$. 6 . Each separate bone was placed over a piece of graph paper lying on an $X$-ray viewing box. The cross which could be seen through the arch. The figures so obtained, whose means are isted, show the following significant differences:

C 1 Larger than all others. $P<0.01$.

Larger than all others except $C$ i. $P<0.01$

C 3 Smaller than $\mathrm{C} 1, \mathrm{C} 2$, and $\mathrm{C} 5$ at $\mathrm{P}<0.01$ and $\mathrm{C} 6$ at $\mathrm{P}<0.05$ and not significantly different from $C 4$.

C 4 Smaller than all but $C 3$ at $P<0.01$ and not significantly different from $C 3$. $C 5$ Smaller than $C 1, C 2$ at $P<0.01$. Larger than $C 3$ and $C 4$ at $P<0.01$. Not diferent from $\mathrm{C} 6$.

C 6 Smaller than $C 1$ and $C 2$ at $P<0.01$. Larger than $C 3$ at $P<0.05$. Large Thus the canal tapers to its narrowest at $C 3$ and $C 4$ and then enlarges slightly.

Thus there is $50 \%$ more room in the canal at $\mathrm{C} 1$ than at $\mathrm{C} 2$ (in accordance with the rotatory function of the atlas) and $14 \%$ more room between $\mathrm{C} 2$ and $\mathrm{C} 3$. However, this does not offer any real explanation for the relatively good prognosis for injuries at $\mathrm{C} 3-4$, where the canal is at its narrowest, and where the anteroposterior mobility is only $3 \frac{1}{2}^{\circ}$ less than the maximum at C5-6. On the other hand, the disc is only $4 \mathrm{~mm}$. thick at that level, and therefore the joint may be more stable than those lower down.

The larger diameter of the spinal canal at the upper levels is not the only factor in the improved prognosis for this sort of injury, however; part of the better outlook lies in the nature of the injury itself, irrespective of the cause (Table IV).

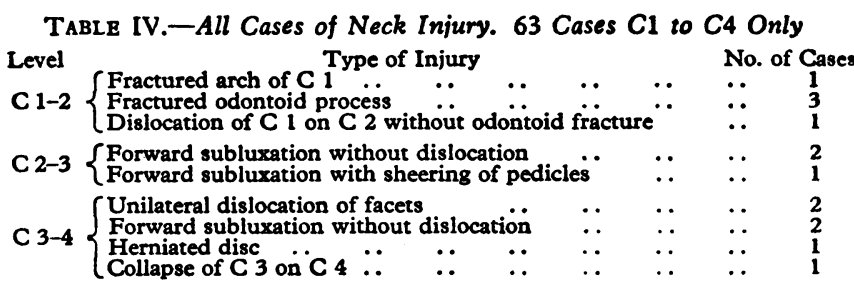

At the C1-2 level the injury may be a fracture of the arch of the $\mathrm{Cl}$ vertebra or of the odontoid process. The dislocation is usually slight, though even massive dislocation may be without signs. At the C2-3 and C3-4 levels partial subluxation of one 
vertebra on the other with little vertebral displacement and with minimal involvement of the spinal cord is commonest. The only fatality at the levels $\mathrm{C} 1$ to $\mathrm{C} 3-4$ was associated with a collapse of $\mathrm{C} 3$ on $\mathrm{C} 4$ with encroachment of fragments on the spinal canal and cord compression, an injury very reminiscent of those occurring at lower levels, and indeed caused in a similar fashion and not by a sack. Below the C3-4 level the commonest injuries are overriding of one or both articular facets in a fracturedislocation or compression fracture of a vertebra, both of which encroach on the space of the spinal canal and cause serious compression and permanent damage. Thus in the upper cervical regions there is not only less displacement of the bones one on the other but a larger canal round which dislocative movements can take place.

Injury to the cervical spine occurring in porters carrying heavy loads on their heads is uncommon considering the enormous numbers of sacks that are transported in this fashion. None the less, such injuries do occur. They seem more likely to involve a higher level of the cervical region than do injuries due to other causes, and are more likely to be associated with a good rather than a poor prognosis for recovery.

\section{Summary}

In Rhodesia many heavy sacks are carried on porters' heads, yet back injuries are infrequent, only 14 cases having been seen in 10 years. Unlike most neck injuries these affect the upper rather than the lower cervical regions, and it is thought that the forces at work are more rotational than flexional.

$X$-ray studies show that when loaded with a $200-\mathrm{lb}$. $(90.7 \mathrm{~kg}$.) sack the normal cervical spine assumes a vertical position and the discs become compressed. Forward angulation occurs where the discs are weak, and may predispose to injury either at that level or in the region of compensatory hyperextension above.

The prognosis in the neck injuries largely depends on the level affected-the higher the injury the better the prognosis. This is probably because the cross-sectional area of the spinal canal is larger in the upper cervical regions, thus allowing more movement of vertebrae before the cord is involved, while the fractured vertebrae themselves show less bony displacement than when the lower levels are involved.

I wish to express my gratitude to Dr. W. M. Castle for her assistance with the statistical studies.

\section{REFERENCES}

Blockey, N. J., and Purser, D. W. (1956). F. Bone ft Surg., 38B, 794. Crandall, P. H., and Hanafee, W. N. (1964). Amer. F. Roentgenol., 92, 1260

Juhl, J. H., Miller, S. M., and Roberts, G. W. (1962). Radiology, 78,

Niemeyer, T., and Penning, L. (1963). F. Bone ft Surg., 45A, 1671

Norton, W. L. (1962), 7. Bone ft Surg., 44A, 115

Pallis, C., Jones, A. M. and Spillane, J. D. (1954), Brain, 77, 274

Payne, E. E. (1959). Neurochirurgia (Stuttg.), $1,178$.

Rogers, W. A. (1957). ₹. Bone 7t Surg., 39A, 341.

Todd, T. W., and Pyle, S. I. (1928). Amer. F. phys. Anthrop., 12, 321.

\title{
Dose of Gentamicin in Patients with Normal Renal Function and Renal Impairment
}

\author{
J. C. GINGELL,* M.B., B.CH., F.R.C.S., F.R.C.S.ED.; PAMELA M. WATERWORTH, † F.I.M.L.T.
}

Brit. med.F., 1968, 2, 19-22

Gentamicin is a broad-spectrum antibiotic belonging to the amino-glycoside group, which includes streptomycin, neomycin, and kanamycin (Weinstein et al., 1963). In-vitro studies have shown it to be bactericidal against a wide range of Grampositive and Gram-negative bacteria, including Pseudomonas aeruginosa, Proteus, and " resistant staphylococci" (Weinstein et al., 1963 ; Rubenis et al., 1963 ; Rabinovich et al., 1963 ; Barber and Waterworth, 1966). Early clinical trials in the United States of America have shown gentamicin to be most effective in the treatment of infection of the urinary tract (Bulger et al., 1963 ; Jao and Jackson, 1964 ; Klein et al., 1964). The most serious side-effect of the antibiotic is that of permanent damage to the vestibular division of the eighth nerve. In these early trials (Sweedler et al., 1963 ; Bulger et al., 1963 ; Jao and Jackson, 1964) a number of patients were rendered ataxic with an impaired sense of balance due to vestibular damage. It has since been advised by the manufacturers that a serum level of $10 \mu \mathrm{g} . / \mathrm{ml}$. should not be exceeded. As gentamicin is excreted almost entirely by glomerular filtration (Black et al., 1963) the serum and tissue levels of the antibiotic are largely dependent on renal function. If the latter is Impaired and the dosage of the drug is not reduced then abnormally high and possibly toxic levels may accumulate in the blood and tissues.

Unfortunately these early mishaps have had the effect of making us unduly cautious about this potentially valuable anti-

* Registrar, Department of Urology.

t Research Assistant, Department of Bacteriology.

Royal Postgraduate Medical School, London W.12. biotic. The usually recommended dosage of $40 \mathrm{mg}$. 12-hourly appears to be inadequate to be of any useful therapeutic value in pseudomonal infections and was the subject of a preliminary report (Darrell and Waterworth, 1967).

As the therapeutic index of the antibiotic is narrow, great care has to be exercised in the size of dose and frequency of administration. This is particularly evident in patients with impaired renal function who are often the most likely to benefit from its use in the treatment of resistant urinary infections. We have therefore recorded the serum levels obtained in normal subjects and non-uraemic and uraemic patients receiving gentamicin in order to gain more information regarding dosage.

\section{Material and Methods}

A single intramuscular injection of $80 \mathrm{mg}$. of gentamicin was given to volunteers with normal renal function. Blood was taken for measurement of serum levels at half, one, two, three, six, and eight hours after administration. The same dose was also given to patients undergoing intermittent haemodialysis and to patients undergoing dietary management of chronic renal failure. Serum levels were determined in this group at intervals up to 72 hours after injection. Further serum levels were obtained from patients with varying degrees of renal impairment undergoing treatment with gentamicin for resistant urinary tract infections. In this latter group peak and trough serum levels after repeated administration were taken to ensure that there was no tendency to accumulation to toxic 